DOI 10.15593/2224-9354/2017.2.4

УДК 316.334 .55

Н.Л. Антонова, М.В. Клейменов

\title{
ПАТЕРНАЛИСТСКИЕ ОРИЕНТАЦИИ В СИСТЕМЕ МЕДИЦИНСКОГО ОБСЛУЖИВАНИЯ НА СЕЛЕ
}

\begin{abstract}
В статье раскрываются особенности современного взаимодействия медицинского персонала и пациентов, включенных в систему медицинского обслуживания на селе. На основе социологического исследования, проведенного в Курганской и Свердловской областях, утверждается, что медицинские работники и пациенты ориентированы на воспроизводство патерналистской модели взаимодействия, в которой врач выступает в роли отца, берущего на себя ответственность за здоровье пациента. Основными принципами патернализма являются ведущая роль медицинского работника и жесткий контроль за выполнением всех предписаний и рекомендаций. Данные опроса пациентов $(n=300)$ свидетельствуют, что 64,8 \% сельчан полагает, что на приеме врачи, фельдшеры и медсестры исполняют роль наставников; 54 \% опрошенных считают, что медперсонал должен жестко управлять пациентами; 58,3 \% респондентов ожидают от медработников заботу, а 52,0 \% - эмоциональную поддержку; 78,7 \% пациентов уверены, что медицинский работник требует выполнения предписаний и рекомендаций, а 34,8 \% - уважения. В ходе стандартизированного интервью с медицинским персоналом $(n=16)$, работающим в сельских поселениях, было выявлено, что для большей части информантов уважение к профессиональной деятельности врача становится основой успешного взаимодействия, а в процессе приема пациент нуждается в проявлении заботы о нем. Материалы, полученные в ходе исследования, выявили влияние пола, возраста, уровня образования и самооценки состояния здоровья опрошенных пациентов на патерналистские ориентации в системе медицинского обслуживания. Роль отца, опекуна и наставника предписывается медицинскому персоналу чаще со стороны женщин пожилых пациентов, сельчан, имеющих среднее общее и среднее профессиональное образование, а также больных с низкой самооценкой состояния здоровья.

Ключевые слова: взаимодействие, медицинские работники, медицинское обслуживание, здравоохранение, патернализм, пациенты, село.
\end{abstract}

Медицинское обслуживание на селе в современных условиях претерпевает значительные изменения, которые касаются, прежде всего, сокращения лечебных учреждений. Так, если в 2005 году численность больничных организаций (больницы, медико-санитарные части, диспансеры и пр.) в сельских поселениях России составляла 3659 учреждений, то к 2014 году их осталось всего 1064. Сокращаются и амбулаторно-поликлинические учреждения: в 2005 году их насчитывалось 7495, а в 2014 году - 3064. К 2014 году на селе осталось лишь 17 медицинских организаций, имеющих стационары [1, с. 89-94].

Сегодня в европейской и американской системе медицинского обслуживания активно развиваются рыночные отношения, которые затрагивают взаимо-

(c) Антонова Н.Л., Клейменов М.В., 2017

Антонова Наталья Леонидовна - д-р социол. наук, профессор кафедры прикладной социологии ФГАОУ ВО «Уральский федеральный университет имени первого Президента России Б.Н. Ельцина», e-mail: n-tata@mail.ru.

Клейменов Михаил Вячеславович - аспирант кафедры прикладной социологии ФГАОУ ВО «Уральский федеральный университет имени первого Президента России Б.Н. Ельцина», e-mail: k-mihaell@mail.ru. 
действие врачей и пациентов. Однако в российском здравоохранении, фундаментом которого более семидесяти лет было оказание бесплатной медицинской помощи населению, формула «товар - деньги - товар» работает слабо. По результатам исследования О.А. Чеботаревой [2, с. 22], в 2006 году среди городских и сельских врачей Южного федерального округа выявлено, что 56 \% являются активными сторонниками патернализма в медицине, 57 \% опрошенных сами решают, какой объем информации о заболевании и лечении предоставлять больным. Если в крупных городах пациенты и врачи включаются в рыночную систему медицинских услуг (платных, альтернативных и пр.), то в сельской глубинке и по сей день воспроизводятся принципы патернализма.

Патернализм как идеология связан с доминантной ролью патерналиста (индивид, социальная группа), которому обязаны подчиниться другие акторы взаимодействия. Это классическая модель взаимодействия между врачами и пациентами, которая строится на основе доверия больных медицинскому персоналу. В этой модели врач выступает в роли отца, берущего ответственность за здоровье и жизнь пациента, его отношение к больному напоминает взаимоотношения между отцом и ребенком [3, с. 108]. Как отмечает И.Б. Назарова, российские пациенты (как жители городов, так и жители сел) в большинстве случаев отдают первенство принятия решению специалисту, рассчитывая на его компетентность [4].

Патерналистский тип взаимодействия наиболее широко тиражируется в системе сельского медицинского обслуживания. Об этом свидетельствуют результаты проведенного нами социологического исследования, основной целью которого стал анализ моделей взаимодействия медицинских работников и сельских пациентов. Исследование проведено в 2016, 2017 годах в Далматовском районе Курганской области и Камышловском районе Свердловской области, всего было опрошено 600 пациентов (300 респондентов в каждом районе, квотный вид отбора, воспроизводящий его половозрастную структуру) и 16 медицинских работников (сплошной отбор: врачи, фельдшеры, медицинские сестры).

Обратимся к анализу ролевых ожиданий и ролевого исполнения социальных общностей, включенных в систему медицинского обслуживания. В нашей исследовательской концепции определены два основных вектора анализа. Первый вектор связан с ожиданиями, как медработников, так и пациентов в процессе взаимодействия. Второй вектор касается исполнения роли медицинского работника и роли пациента во взаимодействии. При этом одной из задач исследования стал сравнительный анализ оценок и суждений ролевых ожиданий и ролевого исполнения медперсонала и пациентов.

Большая часть пациентов предполагает, что медперсонал, прежде всего, ожидает от пациентов выполнение всех предписаний врача $(78,7$ \%). Медицинские работники сельских поселений, однако, иного мнения: лишь 3 информанта из 16 отмечают, что ожидают от пациентов соблюдения рекомендаций. Патерна- 
лизм был всегда доминирующим типом взаимодействия врачей и пациентов в России: врач должен быть доброжелательным с пациентом, но и требовательным профессионалом, нуждающимся в дисциплинированном пациенте [5, с. 230]. Вместе с тем для медицинских работников наиболее ценным в процессе взаимодействия выступает получение уважения со стороны пациентов. Несмотря на тот факт, что опрошенные нами врачи, фельдшеры и медсестры отмечают проявление на практике уважительного отношения, тем не менее встречается хамство и оскорбления со стороны больных. Как отмечает один из врачей, пациенты могут прийти на прием в алкогольном опьянении «...выпивщие... - с ними взаимопонимания не построишь» (врач, стаж работы 43 года).

Поскольку отношения в патерналистской модели взаимодействия подобны отношениям родителя и ребенка, постольку основными принципами являются не только уважение к медицинскому работнику и выполнение его рекомендаций, но и забота, эмоциональная поддержка. По результатам опроса 58,3 \% пациентов ожидают получить в процессе взаимодействия заботу и уход, 52 \% - эмоциональную поддержку. Забота и поддержка пациента заключают в себе обеспечение и охрану физического и психологического комфорта посетителя медицинского учреждения, в том числе и обходительность врача во время консультации и приема пациентов, и осторожность во время анамнеза (сбора информации), и аккуратность при манипуляции (осмотре пациентов) [6]. Вместе с тем только $39,5 \%$ респондентов считают, что в ролевом поведении медперсонала проявляется забота, 39,3 \% отмечают эмоциональную поддержку.

Сами медработники противоречивы в своих суждениях. Так, по их мнению, уход и опека занимают лидирующие позиции в системе ожиданий пациентов (10 информантов), однако на практике лишь третья часть опрошенных предлагает попечительство своим больным. Медперсонал считает, что оказывает эмоциональную поддержку (12 информантов), несмотря на тот факт, что она практически не востребована со стороны пациента (3 информанта).

Вопрос эмоциональной поддержки и безопасности является одним из центральных в анализе взаимодействия основных общностей, включенных в систему медицинского обслуживания. По мнению Н.В. Майсак и С.И. Маджаевой [7], на отношения между пациентом и врачом влияет специализация последнего. Например, хирурги более эмоционально черствые, нежели участковые врачи-терапевты, так как они практически не общаются с пациентами, а информацию о нем и его заболевании получают из медицинской карты.

В отличие от врачей пациенты весьма чувствительны и стремятся получить дополнительную информацию о себе и своем заболевании, например, по тембру голоса врача, быстроте его речи и невербальным жестам, которые он проявляет в процессе сбора анамнеза, установки диагноза и назначения диагностических и лечебных процедур. Отсюда для врача важным становятся владение собственными эмоциями и умение «считывать» их у больного. Та- 
кого рода эмпатия позволяет лучше понять причины заболевания и поставить верный диагноз [5, с. 223-224; 8; 9, с. 19].

Рассматривая эмоциональную поддержку и заботу в системе взаимодействия медицинского персонала и пациентов, следует обратиться и к феномену эмоционального выгорания. Эмоциональное выгорание можно рассматривать, во-первых, как «следствие внутриличностного конфликта, обусловленного рационализацией ценности материального благополучия» [10]. Медицинские работники становятся заложниками социального противоречия между долгом проявить заботу к больному и насущной необходимостью зарабатывать денежные средства, чтобы выжить в российском обществе, переживающем постоянные экономические кризисы. Во-вторых, синдром эмоционального выгорания связан с особенностями профессиональной деятельности медицинского персонала. Врач постоянно находится в состоянии стресса, отсюда его профессиональные манипуляции доведены до автоматизма, который, безусловно, превращает пациента в поломанный механизм, требующий починки. Результаты исследования свидетельствуют, что сельские врачи практически не используют механистический подход к пациенту, поскольку общинный характер образа жизни села снижает социальную дистанцию между жителями и провоцирует внутриролевые конфликты: врач одновременно выступает другом, соседом и т.д.

Патернализм как идеология связан с доминантной ролью патерналиста (индивид, социальная группа), которому обязаны подчиниться другие субъекты взаимодействия. Контроль над ними есть благо, прежде всего, для них самих. Патернализм основан на принципах подчинения, подчеркивающих роль патерналиста как заботливого патрона. Контроль врача над пациентами нашел поддержку и у сельских пациентов: 54 \% опрошенных считают, что врачи должны жестко ими управлять, а каждый третий опрошенный сельчанин считает, что на приеме в сельской больнице он чувствует себя ребенком или учеником.

Вполне очевидна зависимость предписываемой социальной роли наставника медработнику со стороны пациентов от оценки состояния здоровья последних: чем хуже оценка состояния здоровья пациента, тем скорее он будет считать врача отцом и начальником. Уровень образования также оказывается важным фактором для формирования патерналистского образа врача: пациенты со средним общим и средним профессиональным образованием считают, что роль врача на приеме в сельской больнице соответствует патерналистскому типу взаимодействия. Интересной видится зависимость возраста пациента от его представлений о роли медработника: чем старше пациент, тем чаще он видит во враче отца или наставника. Этот факт опровергает представление о старшем поколении как носителе знаний и опыта, его готовности опекать и наставлять; при получении медицинского обслуживания «надеваются» социальные роли ребенка и послушника.

Что касается влияния пола респондента на оценку социальной роли медработника, то материалы опроса показали, что женщины чаще, чем мужчины 
на приеме определяют врача в качестве опекуна. Нельзя не согласится с мнением Ю.В. Филатовой, которая утверждает, что женские заболевания (например, гинекологические заболевания) нуждаются в ранней диагностике, отсюда женщины должны чаще подвергать осмотру собственный организм, им необходимо выстраивать связи с медицинским работником таким образом, чтобы последний уделял больше внимания любому даже самому подозрительному анализу [11]. М. Нэпп и Д. Холл пишут о том, что женщины чаще улыбаются, проявляют самые различные невербальные жесты (кивают головой и др.), и временами это создает иллюзию зависимости женщины от врача, хотя на самом деле она выстраивает максимально выгодное для нее взаимодействие с медицинским персоналом [12, с. 249]. Отсюда наблюдаются гендерные различия в построении моделей взаимодействия с медперсоналом, при этом патерналистские ориентации характерны для женской общности.

Таким образом, оценка состояния здоровья, уровень образования, возраст и пол пациентов влияют на воспроизводство патернализма в системе взаимодействия общностей при получении медицинской помощи. Однако важной видится постановка вопроса о влиянии патерналистских ориентаций при получении медицинских услуг на состояние здоровья индивидов и их здоровьесберегающее поведение. Так, волгоградский исследователь А.А. Богатырев [13] отмечает значимость феномена приобретенной беспомощности (learned helplessness), который является продуктом социализации индивида и ограничивает его социальнопсихологический потенциал. Автор пишет, что патернализм усугубляет состояние явной (осознаваемой) беспомощности у пациента. Результаты нашего опроса также демонстрируют, что патерналистская роль врача снижает ответственность за состояние здоровья у пациента.

Обратимся к анализу ограничения действий пациентов в процессе взаимодействия с медработниками, который характерен для патерналистского типа взаимодействия. Пациенты, находясь в зависимой роли по отношению к обладающему специальными знаниями профессионалу, оценивают строже поведение сельского врача, наделяя его диктаторскими полномочиями. Медработники российского села считают, что их принципы контроля нежесткие и что они меньше всего желают ограничивать поведение пациентов. Ограничение действий пациентов может быть связано как с личностными качествами врачей, так и с самим процессом оказания медицинских услуг: врач может оказать помощь только при наличии четкого диагноза, который опирается на выраженные симптомы определенного заболевания [14].

В целом, по нашим данным, в системе медицинского обслуживания на селе патерналистский тип взаимодействия характеризуется следующим: 64,8 \% сельчан полагает, что на приеме сельские врачи/фельдшеры/медсестры исполняют роли отца или наставника; 54 \% опрошенных считают, что медперсонал должен жестко управлять пациентами; 58,3 \% респондентов ожидают от медработников заботу и 52,0 \% - эмоциональную поддержку; 78,7 \% пациентов уверены, что 
медицинский работник требует выполнения всех своих предписаний и рекомендаций, а 34,8 \% - уважения. Что касается оценок модели взаимодействия медицинским персоналом, то для большей части информантов (10 из 16) уважение к профессиональной деятельности врача выступает основой успешного взаимодействия, а в процессе приема пациент нуждается в проявлении заботы о нем.

Избавиться от господства патерналистских ориентаций, таких как ведущая роль врача во время лечения и контроль над пациентом, в ближайшее время не представляется возможным. Даже введение письменного контракта между врачом и пациентом в частных клиниках выявляет элементы патернализма в написанных договорах [15]. Д.В. Михальченко [16] на основе анкетного опроса пациентов стоматологических клиник полагает, что из-за неравномерного потока пациентов российский медперсонал использует патерналистские нормы поведения. Автор считает, что патернализм свидетельствует о низкой культуре предоставления медицинских услуг. В.Т. Ягупова и ее коллеги [17] показали, что врачам удобнее работать с пациентами в патерналистской модели взаимодействия при низкой культуре предоставления медицинских услуг в российской стоматологии.

Несмотря на имеющиеся недостатки патерналистской модели взаимодействия, в частности снижение ответственности пациента за свое здоровье, мы полагаем, что ее ликвидация приведет к трансформации моральных и этических норм, разрушению традиций, накопленных отечественной системой здравоохранения. Мы полагаем, что введение рыночных отношений в медицинское обслуживание на селе необходимо с учетом сельского образа жизни и специфики повседневных практик сельчан. Агрессивная политика, ориентированная на нивелирование патернализма, скорее нанесет вред сельскому пациенту и станет фактором, снижающим эффективность профилактики и лечения.

Статья подготовлена в рамках исследовательского проекта № 16-33-00008, финансируемого Российским гуманитарным научным фондом (РГНФ-РФФИ).

\section{Список литературы}

1. Здравоохранение в России. 2015: стат. сб. / Росстат. - М., 2015. - 174 с.

2. Чеботарева О.А. Патернализм в отечественной медицине: автореф. дис. ... канд. социол. наук / Волгогр. гос. мед. ун-т. - Волгоград, 2006. -22 с.

3. Дьяченко В.Г., Дьяченко С.В. Система взаимоотношений «врач - пациент» // Дальневосточный медицинский журнал. - 2015. - № 2. - С. 106-111.

4. Назарова И.Б. Здоровье и качество жизни жителей России // Социологические исследования. - 2014. - № 9. - С. 139-145.

5. Ефименко С.А. Социология пациента: дис. ... д-ра. социол. наук / Моск. мед. акад. им. И.М. Сеченова. - М, 2007. - 527 с.

6. Бойко В.В., Зыкина Е.А. Медицинский сервис в стоматологии (Часть II) // Институт стоматологии. - 2010. - Т. 1, № 46. - С. 14-17. 
7. Майсак Н.В., Маджаева С.И. Девиативный медицинский дискурс как неэффективный стиль взаимодействия врача и пациента // Астраханский медицинский журнал. - 2010. - № 5. - С. 133-137.

8. Расторгуева Т.И., Проклова Т.Н., Карпова О.Б. Значение невербальной коммуникации для процессов взаимодействия врача и пациента // Бюллетень национального научно-исследовательского института общественного здоровья им. Н.А. Семашко. - 2016. - № 1-2. - С. 127-132.

9. Курылева Н.В. Представления врачей о качествах, обеспечивающих эффективное взаимодействие с пациентом: автореф. дис. ... канд. психол. наук / Костром. гос. ун-т. - Кострома, 2012. - 28 с.

10. Денисов А.А., Терёхина Н.В. Эмоциональное выгорание в профессиональной деятельности (на примере эмпирического исследования эмоционального выгорания у стоматологов) // Развитие личности. - 2015. - № 4. - С. 98-112.

11. Филатова Ю.В. Контексты ценностного отношения женщины к здоровью // Педагогика и психология образования. - 2011. - № 3. - С. 99-104.

12. Нэпп М., Холл Д. Невербальное общение. - СПб.: Прайм-ЕВРОЗНАК, 2004. $-256 \mathrm{c}$.

13. Богатырев А. А. Поведенческие особенности пациентов с приобретенной беспомощностью: сравнительный анализ различных групп пациентов // Фундаментальные исследования. - 2014. - № 12-10. - С. 2245-2250.

14. Карымшакова Т.Г. Конфликтный дискурс как результат коммуникативной неудачи в речевом взаимодействии врача и пациента // Язык, перевод и межкультурная коммуникация: материалы науч.-практ. сем. «Пути и стратегии подготовки специалистов в области межкультурной коммуникации». Улан-Удэ: Изд-во Бурят. гос. ун-та, 2015. - С. 79-85.

15. Шабанова А.С., Боговин Л.В., Колосов В.П. Модели терапевтического взаимодействия врача и пациента // Бюллетень патологии и физиологии дыхания. - 2016. - № 60. - С. 105-110.

16. Михальченко Д.В. Стоматологическая услуга как социальное взаимодействие врача и пациента: автореф. дис. ... д-ра мед. наук / Волгогр. гос. мед. ун-т. - Волгоград, 2012. - 47 с.

17. Врач-стоматолог как исполнитель медицинских услуг / В.Т. Ягупова, Ю.М. Федотова, Е.А. Филюк, Л.Н. Денисенко // Успехи современного естествознания. - 2014. - № 11-3. - С. 22-26.

\section{References}

1. Zdravookhranenie v Rossii [Healthcare in Russia]. Rosstat Publ. Moscow, 2015, 174 p.

2. Chebotareva O.A. Paternalizm v otechestvennoi meditsine [Paternalism in domestic medicine]. Abstract of Ph. D. thesis. Volgograd, Volgogradskii gos. med. un-t, 2006, 22 p. 
3. D'iachenko V.G., D'iachenko S.V. Sistema vzaimootnoshenii "vrachpatsient" [The doctor-patient relationship system]. Dal'nevostochnyi meditsinskii zhurnal, 2015, no. 2, pp. 106-111.

4. Nazarova I.B. Zdorov'e i kachestvo zhizni zhitelei Rossii [Health and quality of life of the Russian citizens]. Sotsiologicheskie issledovaniia, 2014, no. 9, pp. 139-145.

5. Efimenko S.A. Sotsiologiia patsienta [Patient sociology]. Doctor's degree dissertation. Moscow, Moskovskaia med. akademiia im. I.M. Sechenova, 2007, 527 p.

6. Boiko V.V., Zykina E.A. Meditsinskii servis v stomatologii (Chast' II) [Medical service in stomatology (Part II)]. Institut stomatologii, 2010, no. 46, vol. 1, pp. 14-17.

7. Maisak N.V., Madzhaeva S.I. Deviativnyi meditsinskii diskurs kak neeffektivnyi stil' vzaimodeistviia vracha i patsienta [Deviative medical discourse as an ineffective style of doctor-patient interaction]. Astrakhanskii meditsinskii zhurnal, 2010, no. 5, pp. 133-137.

8. Rastorgueva T.I., Proklova T.N., Karpova O.B. Znachenie neverbal'noi kommunikatsii dlia protsessov vzaimodeistviia vracha i patsienta [The importance of non-verbal communication for the processes of doctor-patient interaction]. Biulleten' natsional'nogo nauchno-issledovatel'skogo instituta obshchestvennogo zdorov'ia im. N.A. Semashko, 2016, no. 1-2, pp. 127-132.

9. Kuryleva N.V. Predstavleniia vrachei o kachestvakh, obespechivaiushchikh effektivnoe vzaimodeistvie s patsientom [Doctors vision of the qualities that provide effective interaction with the patient]. Abstract of $\mathrm{Ph}$. D. thesis. Kostroma, Kostromskoi gos. un-t, $28 \mathrm{p}$.

10. Denisov A.A., Terekhina N.V. Emotsional'noe vygoranie v professional'noi deiatel'nosti (na primere empiricheskogo issledovaniia emotsional'nogo vygoraniia $u$ stomatologov) [Emotional burnout in professional activity (case study of emotional burnout of dentists)]. Razvitie lichnosti, 2015, no. 4, pp. 98-112.

11. Filatova Iu.V. Konteksty tsennostnogo otnosheniia zhenshchiny k zdorov'iu [Contexts of axiological attitude of women to health]. Pedagogika i psikhologiia obrazovaniia, 2011, no. 3, pp. 99-104.

12. Nepp M., Kholl D. Neverbal'noe obshchenie [Nonverbal communication]. Saint-Petersburg, Praim-EVROZNAK Publ., 2004, 256 p.

13. Bogatyrev A.A. Povedencheskie osobennosti patsientov s priobretennoi bespomoshchnost'iu: sravnitel'nyi analiz razlichnykh grupp patsientov [Behavioral characteristics of patients with acquired helplessness: a comparative analysis of different patient groups]. Fundamental'nye issledovaniia, 2014, no. 12-10, pp. 2245-2250.

14. Karymshakova T.G. Konfliktnyi diskurs kak rezul'tat kommunikativnoi neudachi v rechevom vzaimodeistvii vracha i patsienta [Conflict discourse as a result of communicative failure the doctor-patient communication]. Iazyk, perevod $i$ mezhkul'turnaia kommunikatsiia: materialy nauchno-prakticheskogo seminara "Puti $i$ strategii podgotovki spetsialistov v oblasti mezhkul'turnoi kommunikatsii" [Proc. Sci. and Pract. Seminar "Ways and strategies of specialists training in the field of intercultural communication"]. Ulan-Ude, Buryat State University Publ., 2015, pp. 79-85.

PNRPU Sociology and Economics Bulletin. 2017. No. 2 
15. Shabanova A.S., Bogovin L.V., Kolosov V.P. Modeli terapevticheskogo vzaimodeistviia vracha i patsienta [Models of doctor-patient therapeutic interaction]. Biulleten' patologii i fiziologii dykhaniia, 2016, no. 60, pp. 105-110.

16. Mikhal'chenko D.V., Stomatologicheskaia usluga kak sotsial'noe vzaimodeistvie vracha i patsienta [Dental service as doctor-patient social interaction]. Abstract of Doctor's degree dissertation. Volgograd, Volgograd. gos. med. un-t Publ., 2012, 47 p.

17. Iagupova V.T., Fedotova Iu.M., Filiuk E.A., Denisenko L.N. Vrachstomatolog kak ispolnitel' meditsinskikh uslug [Dentist as a provider of medical services]. Uspekhi sovremennogo estestvoznaniia, 2014, no. 11-3, pp. 22-26.

Оригинальность статьи - $92 \%$

Получено 31.01.2017

N.L. Antonova, M.V. Kleymenov

\section{PATERNALIST ORIENTATIONS IN HEALTHCARE SYSTEM OF RURAL AREAS}

The article analyzes modern interactions between the patients and medical personnel as the members of healthcare system in rural areas. Based on the finding of sociological research carried in Kurgan and Sverdlovsk Oblast, the authors claim that both medical workers and patients are focused on the reproduction of paternalistic model of interaction. Thus, a doctor acts as a father taking responsibility for a patient's health. Basic principles of paternalism include the leading role of a medical worker along with the strict control of all the instructions and recommendations to be fulfilled. The survey data from 300 patients' responses show that $64.8 \%$ of village residents consider doctors and nurses to act as mentors, $54 \%$ demand strict regulation from medical staff, 58.3 and $52.0 \%$ respectively expect care and support from medical workers, while 78.7 and $34.8 \%$ are sure that medical staff should be demanding as well as respectful. The results of a standardized interview of medical personnel $(n=16)$ working in rural areas showed the relevance of respectful attitude to the professional activity for most of the respondents, as it appears a key factor to the effective interaction with the patients. The results obtained revealed the influence of gender, age, level of education and health self-esteem on the paternalistic orientations in the sphere of medical service. The role of a father, guardian and mentor is often attributed to the medical staff by women, elderly patients, patients having general secondary and secondary vocational education, as well as the patients with a low level of health self-esteem.

Keywords: interaction, medical workers, health service, healthcare, paternalism, patients, rural areas.

Natalya L. Antonova - Doctor of Sociological Sciences, Professor, Dept. of Applied Sociology, Ural Federal University named after the first President of Russia B.N. Yeltsin, e-mail: n-tata@mail.ru.

Mikhail V. Kleymenov - Postgraduate Student, Dept. of Applied Sociology, Ural Federal University named after the first President of Russia B.N. Yeltsin, e-mail: k-mihaell@mail.ru. 